\title{
STRATEGI KEBIJAKAN MENGURANGI FRAUD DALAM KLAIM BPJS DITINJAU DARI PERMENKES NOMOR TAHUN 2015 DIHUBUNGKAN DENGAN ASAS KEMANUSIAAN
}

\author{
Keika Marriska \\ Alumni Program Studi Magister Ilmu Hukum \\ Pascasarjana Universitas Islam Bandung \\ Dokter Spesialis Kandungan RS Muhamadiyah Bandung \\ Email : keikaicha@yahoo.com
}

\begin{abstract}
Abstrak : Program BPJS Kesehatan sebagai penyelenggara Kesehatan dalam pelaksanaanya, ditemukan kendala berupa fraud. Tujuan Penelitian ini adalah Mengetahui terjadinya fraud yang dilakukan peserta, pemberi pelayanan kesehatan, dan pemangku kebijakan dalam hal klaim yang berkaitan dengan BPJS, Implementasi kebijakan Peraturan Menteri Kesehatan Nomor 36 Tahun 2015 dalam mencegah tindakan fraud. Serta mengetahui Strategi pencegahan tindakan fraud dalam klaim BPJS Kesehatan, Metode penelitian yang digunakan adalah yuridis normative, spesifikasi penelitian bersifat deskriptif analisis, Teknik pengumpulan data melalui studi kepustakaan. (1) Mekanisme fraud oleh peserta : pemalsuan status kepesertaan dan kondisi kesehatan; oleh pemberi pelayanan: upcoding, fragmentation,readmisi, no medical value, type of room charge; oleh pembuat kebijakan: menahan pembayaran ke fasilitas kesehatan, membayarkan dana kapitasi tidak sesuai dengan ketentuan; (2) Implementasi Kebijakan: penyusunan kebijakan dan pedoman pencegahan fraud, pengembangan budaya pencegahan fraud, pembentukkan tim pencegahan fraud; (3) Strategi pencegahan fraud: kesadaran pihak terkait terhadap fraud, menentukan standar pelayanan kedokteran.
\end{abstract}

Kata Kunci : Fraud, Klaim BPJS, Permenkes Nomor 36 Tahun 2015.

Abstract: In its implementation, the BPJS Kesehatan program as a health provider, found obstacles in the form of fraud. The purpose of this study is to find out the occurrence of fraud committed by participants, health service providers, and policymakers in terms of claims related to BPJS, Implementation of policies of the Minister of Health Regulation Number 36 of 2015 in preventing fraud. As well as knowing the strategy to prevent fraud in BPJS Health claims, the research method used is juridical normative, the research specification is descriptive analysis, data collection techniques through literature study. (1) Fraud mechanisms by participants: falsification of membership status and health conditions; by service providers: upcoding, fragmentation, readmission, no medical value, type of room charge; by policymakers: withholding payments to health facilities, paying capitation funds, not by the provisions; (2) Policy Implementation: formulating policies and guidelines for fraud prevention, developing a culture of fraud prevention, forming a fraud prevention team; (3) Fraud prevention strategy: awareness of related parties against fraud, determining medical service standards.

Keywords: Fraud, BPJS Claims, Permenkes Number 36 of 2015.

\section{A. PENDAHULUAN}

\section{Latar Belakang}

Kesehatan adalah hak dasar setiap individu dan semua warga negara berhak mendapatkan 
pelayanan kesehatan termasuk masyarakat miskin. Undang-undang Dasar Negara Republik Indonesia Tahun 1945 (UUD 1945) dalam pasal Pasal $28 \mathrm{H}$ ayat (1) menyebutkan bahwa, "Setiap orang berhak hidup sejahtera lahir dan batin, bertempat tinggal, dan mendapatkan lingkungan hidup yang baik dan sehat serta berhak memperoleh pelayanan kesehatan." Dengan demikian kesehatan merupakan hak asasi manusia, sehingga setiap penduduk berhak mendapat pelayanan kesehatan sesuai dengan standar mutu yang telah ditetapkan tanpa memandang kemampuan membayar (Hasbullah Tabrany, $2005:$ 10).

Dalam rangka upaya meringankan biaya pelayanan kesehatan terutama terhadap masyarakat yang tidak mampu, pemerintah telah mengeluarkan kebijakan Jaminan Kesehatan Nasional (JKN) yaitu suatu program pemerintah yang bertujuan memberikan kepastian jaminan kesehatan yang menyeluruh bagi seluruh rakyat Indonesia untuk dapat hidup sehat, produktif dan sejahtera (www.Tnp2k.go.id, diakses 25 April 2018). Program tersebut diintegrasikan ke dalam suatu badan yang dinamakan Badan Penyelenggara Jaminan Sosial Kesehatan (BPJS Kesehatan).

Jaminan Kesehatan Nasional telah dilaksanakan sejak tanggal 1 Januari 2014, berdasarkan amanat Undang-undang Dasar
1945 dan Undang-undang Nomor 40 Tahun 2004 Tentang Sistem Jaminan Sosial Nasional (SJSN) demi tercapainya jaminan kesehatan semesta. Aspek pelayanan kesehatan merupakan aspek yang perlu diperhatikan karena pelayanan kesehatan merupakan kunci keberhasilan dalam penyelenggaraan Jaminan Kesehatan Nasional selain aspek regulasi, kepesertaan, manfaat, keuangan dan kelembagaan (Hubaib Alif Khariza, Program Jaminan Kesehatan Nasional: Studi Deskriptif Tentang Faktor-Faktor Yang Dapat Mempengaruhi Keberhasilan Implementasi Program Jaminan Kesehatan Nasional Di Rumah Sakit Jiwa Menur Surabaya, Jurnal Kebijakan dan Manajemen Publik Volume 3, Nomor 1, Januari - April 2015 : 1).

$$
\text { Undang-Undang SJSN ini }
$$

diharapkan mampu mengembangkan sistem jaminan sosial nasional guna memenuhi kebutuhan masyarakat terhadap pelayanan kesehatan yang bermutu, dan terjangkau oleh masyarakat, sistem ini diselenggarakan dengan model asuransi sosial dengan mekanisme pengumpulan dana dari peserta BPJS (Undang-Undang No. 40 Tahun 2004).

Norma dasar tentang penyelenggaraan jaminan kesehatan tertuang dalam Pasal 2 Undang-Undang SJSN yaitu sistem jaminan sosial nasional diselenggarakan berdasarkan asas 
kemanusiaan, asas manfaat, dan asas keadilan sosial bagi seluruh rakyat Indonesia. Dalam penjelasan Pasal 2 Undang-undang SJSN diuraikan bahwa asas kemanusiaan berkaitan dengan penghargaan terhadap martabat manusia. Asas manfaat merupakan asas yang bersifat operasional menggambarkan pengelolaan yang efisien dan efektif. Asas keadilan merupakan asas yang bersifat idiil. Ketiga asas tersebut dimaksudkan untuk menjamin kelangsungan program dan hak peserta. Ketiga norma dasar ini memberikan gambaran bahwa dorongan untuk mewujudkan keadilan sosial bagi semua bersatu dengan prinsip saling membantu atau beramal demi terwujudnya jaminan sosial (Vladimir Rys, 2011:32).

Upaya pemerintah memberikan pelayanan kesehatan bagi masyarakat secara menyeluruh masih menemui kendala, antara lain adanya potensi fraud (kecurangan) yang menjadi tantangan dalam pelaksanaan good corporate governance, hal demikian banyak ditemui di beberapa negara maju yang mengadopsi sistem jaminan sosial yang serupa dengan Indonesia seperti pelaksanaan jaminan sosial di Amerika, Federal Bureau of Investigation (FBI) mencatat ada sekitar 3$10 \%$ dilakukan baik penyedia layanan kesehatan sebagai provider, peserta JKN dan badan penyelenggara $\mathrm{JKN}$, serta keluhan yang datang dari berbagai pihak seperti manajer rumah sakit maupun dokter terkait dengan rendahnya tarif INACBGs yang diberlakukan dapat mengakibatkan menurunnya pendapatan rumah sakit dan para dokter, persepsi ini dapat memicu terjadinya fraud dalam era JKN (Hasan Sadikin, Wiku Adisasmito, Analisis Pengaruh Dimensi Fraud Triangle dalam Kebijakan Pencegahan Fraud terhadap Program JKN di RSCM, Jurnal Ekonomi Kesehatan Indonesia, Vol 1 Nomor 2, $2016: 28)$.

\section{Fraud dalam Bahasa Indonesia} berarti kecurangan, memiliki arti melakukan kesalahan terhadap kebenaran untuk tujuan mendapatkan sesuatu yang bernilai atas kerugian orang lain atau mendapatkannya dengan membelokkan hukum atau kesalahan atau memberikan keterangan yang salah oleh seseorang atau entitas yang mengetahui hal itu dan dapat menghasilkan sejumlah manfaat yang tidak legal kepada individu, entitas, atau pihak lain.(Yaslis Ilyas, 2015:28).

$$
\text { Tindakan fraud dapat }
$$
dikategorikan sebagai tindakan kriminal. Tindakan fraud ini dapat mencapai $10 \%$ dari total klaim dalam satu tahun dan dapat lebih besar jika tidak dilakukan upaya pencegahan. Namun sampai saat ini, belum ada aturan yang secara eksplisit mengatur hukuman atas tindakan fraud yang dilakukan oleh pihak-pihak dalam asuransi kesehatan. (Direktorat 
Perlindungan dan Kesehatan Masyarakat, 2015:61).

Tindakan fraud dalam sektor kesehatan meliputi tindakan korupsi, penyalahgunaan aset dan pemalsuan pernyataan. Potensi fraud layananan kesehatan ini muncul dan dapat menjadi semakin luas karena adanya tekanan dari sistem pembiayaan yang baru berlaku di Indonesia,adanya kesempatan karena minimnya pengawasan, serta ada pembenaran saat melakukan tindakan ini.

Berdasarkan penelitian yang dilakukan oleh Indonesian Corruption Watch (ICW), bersama dengan 14 organisasi pemantau lainnya ditemukan berbagai kecurangan (fraud) dari tingkat pasien, Rumah Sakit (RS), Puskesmas hingga penyedia obat. Penelitian itu dilakukan di Aceh, Sumatera Utara, Riau, Sumatera Barat, DKI Jakarta, Jawa Barat, Jawa Tengah, Jawa Timur, Kalimantan Barat, Kalimantan Timur, Sulawesi Selatan, Sulawesi Utara, NTT dan NTB. Tujuan penelitian ini untuk mendorong perbaikan layanan jaminan kesehatan dan layanan fasilitas kesehatan bagi peserta JKN, khususnya pagi peserta Kartu Indonesia Sehat (KIS) maupun Penerima Bantuan Iuran (PBI) serta memberikan gambaran titik rawan kecurangan dalam program.

Pada penelitian tersebut, ditemukan 49 kecurangan program JKN yang terdiri dari pelaku peserta BPJS sebanyak 10 temuan, BPJS Kesehatan 1 temuan, Fasilitas Kesehatan 36 temuan, dan penyedia obat sebanyak 2 temuan.

Data ICW periode 2010-2016 menunjukkan peringkat obyek korupsi dana jaminan kesehatan yang diselenggarakan BPJS semakin meningkat. Hal itu terlihat dari 26 kasus dengan nilai kerugian negara mencapai Rp 62,1 miliar.

Besarnya potensi kerugian yang ditimbulkan, mendorong pemerintah menerbitkan Peraturan Menteri Kesehatan Nomor 36 Tahun 2015 Tentang Pencegahan Kecurangan (Fraud) dalam Pelaksanaan Program Jaminan Kesehatan Pada Sistem Jaminan Sosial Nasional (selanjutnya disebut Peraturan Menteri Kesehatan Nomor 36 Tahun 2015), langkah ini merupakan upaya untuk mencegah timbulnya kerugian yang dapat terjadi pada fasillitas layanan kesehatan. Namun sejak diluncurkan April 2015 lalu, peraturan ini belum optimal dijalankan. Dampak fraud dalam pelayananan kesehatan berpotensi semakin banyak terjadi dan tidak diiringi dengan sistem pengendalian yang mumpuni. (Hanevi Djasri, et.al, Korupsi dalam Pelayanan Kesehatan di Era JKN : Kajian Besarnya Potensi dan Sistem Pengendalian Fraud, Jurnal INTEGRITAS Volume 02 Nomor 1 Tahun $2016: 116)$. 
Bentuk kegiatan anti fraud yang tertuang dalam Peraturan Menteri Kesehatan Nomor 36 Tahun 2015 mencakup pembangunan kesadaran anti fraud, pelaporan, deteksi, investigasi, dan pemberian sanksi.

Kegiatan pembangunan kesadaran melalui sosialisasi dan edukasi Peraturan Menteri Kesehatan Nomor 36 Tahun 2015 belum berjalan baik. Tugas edukasi, sosialisasi, pembinaan, dan pengawasan upaya anti fraud bagi seluruh aspek yang berpotensial fraud merupakan tanggungjawab kementerian dan Dinas Kesehatan tingkat Provinsi maupun Kabupaten/Kota (Permenkes No. 36 Tahun 2015). Pada kenyataannya masih banyak Dinas Kesehatan yang belum tahu mengenai peraturan ini sehingga belum banyak melakukan aksi untuk mengendalikan fraud layanan kesehatan.

Kegiatan pelaporan dugaan fraud layanan kesehatan juga belum optimal karena ketiadaan sarana untuk melapor. Kalaupun ada informasi terkait potensi fraud yang dilaporkan, tindak lanjut dari laporan tersebut belum pasti. Proses deteksi fraud terkendala akibat minimnya teknologi untuk mengolah data dan informasi potensi fraud. Data yang dapat digunakan untuk melakukan deteksi potensi fraud salah satunya adalah klaim BPJS Kesehatan. Melalui data ini dapat dianalisis di titik mana terjadi kecurangan dan pelaku kecurangan. Pengolahan data ini menggunakan suatu sistem teknologi yang sensitif terhadap potensial fraud, namun saat ini teknologi olah data seperti itu belum ada di Indonesia atau masih dalam tahap pengembangan.

Proses investigasi juga masih terkendala karena saat ini belum ada investigator khusus untuk penyidikan kasus-kasus fraud layanan kesehatan di Indonesia. Peran investigator dalam upaya anti fraud sangat krusial karema memiliki kewenangan untuk membuktikan sebuah tindakan fraud, besar kerugian yang dihasilkan, hingga rekomendasi sanksi. Saat ini proses investigasi potensi fraud masih dilakukan secara sederhana yaitu dengan membandingkan sebuah dugaan fraud dengan aturan-aturan dari Kementerian Kesehatan maupun BPJS Kesehatan. Pihak yang melakukan perbandingan data dan aturan adalah pihak yang merasa dirugikan. Dampaknya, bias kepentingan sangat kental dalam proses ini.

\section{Dalam Peraturan Menteri}

Kesehatan Nomor 36 Tahun 2015 telah disebutkan sanksi-sanksi administrasi yang dapat diberikan kepada pelaku fraud. Namun, mekanisme penerapan sanksi ini belum jelas. Pihak yang berwenang daalm memberi sanksi adalah kementerian dan dinas kesehatan. Saat ini belum diketahui dengan pasti apakah sudah ada pelaku 
fraud yang secara resmi diberi sanksi oleh kementerian maupun dinas kesehatan. Salah satu bentuk sanksi yang diketahui sudah dijalankan adalah pengembalian dana oleh BPJS Kesehatan kepada fasilitas kesehatan maupun sebaliknya. Tetapi mekanisme pengembalian dana ini juga belum jelas hanya dilakukan secara kekeluargaan antara kedua belah pihak.

Dampak dari tindakan fraud dalam pelayanan kesehatan sangat merugikan negara dana rakyat, sehingga fraud dikategorikan sebagai kejahatan/kriminal dan dapat dikategorikan sebagai pemalsuan dan penipuan, hal tersebut tentu saja akan mendapatkan konsekuensi hukum pidana. Peraturan dan perundangundangan yang dapat dipakai untuk menjerat pelaku fraud ini adalah KUHP, menggunakan pasal penipuan secara umum sebagaimana terdapat pada pasal 378 KUHP dan dalam pasal 381 KUHP.

Fraud dalam program JKN dapat pula dijerat dengan pasal pemalsuan dalam KUHP yaitu pemalsuan surat Pasal 263 KUHP - 276 KUHP. Bila ditinjau lebih lanjut, maka fraud dalam pelayanan JKN lebih mengena pada pemalsuan surat. Pemalsuan dalam surat-surat dianggap lebih bersifat mengenai kepentingan masyarakat, yaitu kepercayaan masyarakat kepada isi surat-surat daripada bersifat kepentingan pribadi yang mungkin secara langsung dirugikan dengan pemalsuan surat ini.

Bentuk-bentuk fraud dalam pelaksanaan JKN, dapat diuraikan bahwa perbuatan fraud adalah merupakan perbuatan yang dapat dihukum menurut hukum pidana. Tindak pidana yang paling sering terjadi dalam pelaksanaan JKN adalah tindak pidana pemalsuan dan penipuan, dan pasal yang terkaitnya adalah Pasal 263 KUHP, Pasal 266 KUHP, Pasal 378 KUHP dan Pasal 381 KUHP, telah melansir suatu perbuatan pidana yang dilakukan terhadap pelaksanaan JKN.

Maraknya fraud dalam pelayanan kesehatan dan kebijakan anti fraud yang sampai saat ini implementasinya belum dirasakan optimal, maka diperlukan strategi pencegahan tindakan fraud dalam klaim BPJS Kesehatan.

\section{Identifikasi Masalah}

1. Bagaimana terjadinya Fraud yang dilakukan oleh peserta, pemberi pelayanan kesehatan, dan pemangku kebijakan dalam hal klaim yang berkaitan dengan BPJS?

2. Bagaimana implementasi Kebijakan Peraturan Menteri Kesehatan Nomor 36 Tahun 2015 dalam mencegah tindakan fraud?

3. Bagaimana strategi pencegahan tindakan fraud dalam klaim BPJS Kesehatan, agar tidak terjadi lagi kecurangan di masa yang akan datang? 


\section{Tujuan Penelitian}

Tujuan penelitian dalam penelitian ini adalah :

1. Mengetahui terjadinya fraud yang dilakukan peserta, pemberi pelayanan kesehatan, dan pemangku kebijakan dalam hal klaim yang berkaitan dengan BPJS

2. Mengetahui implementasi kebijakan Peraturan Menteri Kesehatan Nomor 36 Tahun 2015 dalam mencegah tindakan fraud.

3. Mengetahui Strategi pencegahan tindakan fraud dalam klaim BPJS Kesehatan, agar tidak terjadi lagi kecurangan di masa yang akan datang.

\section{Metode Penelitian}

Pendekatan yang digunakan dalam penelitian ini adalah yuridis normatif atau penelitian hukum normatif, yakni dengan mempelajari dan menelaah hukum sebagai suatu kaidah atau sistem kaidah-kaidah hukum normatif di bidang hukum. (Johny Ibrahim, $2005:$ 49-52).

Dalam penyusunan dan penulisan penelitian ini dipergunakan spesifikasi penelitian yang bersifat deskriptif analisis. Penelitian deskriptif analitis berupaya mengungkapkan aturan perundangundangan yang berkaitan dengan teoriteori hukum yang menjadi objek penelitian. Demikian juga hukum dalam pelaksanaannya di masyarakat yang berkenaan dengan objek penelitian.

Teknik pengumpulan data dalam penelitian ini dilakukan melalui cara penelitian kepustakaan (Library Research) melalui penelusuran bahan pustaka. (Soerjono Soekanto, 2001 : 14). Bahan pustaka tersebut meliputi bahan hukum primer (primer sources of authorities) berupa ketentuan perundang-undangan, bahan hukum sekunder (secondary sources of authorities) berupa buku-buku teks, litaratur dan tulisan-tulisan para ahli pada umumnya. Selain itu dilakukan penelusuran landasan teoritis berupa pendapat-pendapat para ahli atau informasi dari pihak berwenang. (Op.Cit : 47-56).

Bahan-bahan yang dikumpulkan dianalisis dengan menggunakan teknik analisis kualitatif normatif yaitu dengan cara melakukan penafsiran, korelasi, dan perbandingan terhadap-bahan-bahan hukum.

\section{B. PEMBAHASAN}

\section{Tindakan Kecurangan Dalam}

\section{Pelayanan BPJS Kesehatan}

Dalam Permenkes Nomor 36 Tahun 2015, disebutkan bahwa tindakan kecurangan yang terjadi dalam pelayanan kesehatan tercantum dalam Bab II mengenai tindakan kecurangan JKN. Pada 
pasal 2, Tindakan kecurangan JKN dapat dilakukan oleh:

a. peserta,

b. petugas BPJS Kesehatan,

c. pemberi pelayanan dan kesehatan dan/atau

d. penyedia obat dan alat kesehatan.

Dalam Pasal 3, Tindakan kecurangan JKN yang dilakukan oleh peserta, sebagaimana dimaksud dalam Pasal 2 huruf a, meliputi :

a. Membuat pernyataan yang tidak benar dalam hal eligibilitas (memalsukan status kepesertaan) untuk memperoleh pelayanan kesehatan.

b. Memanfaatkan haknya untuk pelayanan yang tidak perlu (unnecessary services) dengan cara memalsukan kondisi kesehatan.

c. Memberikan gratifikasi kepada pemberi pelayanan agar bersedia memberi pelayanan yang tidak sesuai/ tidak ditanggung.

d. Memanipulasi penghasilan agar tidak perlu membayar iuran terlalu besar.

e. Melakukan kerjasama dengan pemberi pelayanan untuk mengajukan klaim palsu.

f. Memperoleh obat dan atau alat kesehatan yang diresepkan untuk dijual kembali, dan atau

g. Melakukan tindakan kecurangan JKN lainnya selain huruf a sampai dengan huruf f.
Dalam Pasal 4, Tindakan kecurangan JKN yang dilakukan oleh petugas BPJS Kesehatan sebagaimana dimaksud dalam Pasal 2 huruf b, meliputi :

1. Melakukan kerjasama dengan peserta dan/atau fasilitas kesehatan untuk mengajukan klaim palsu;

2. Memanipulasi manfaaat yang seharusnya tidak dijamin agar dapat dijamin;

3. Menahan pembayaran ke fasilitas kesehatan/rekanan dengan tujuan memperoleh keuntungan pribadi;

4. Membayarkan dana kapitasi tidak sesuai dengan ketentuan; dan/atau

5. Melakukan tindakan kecurangan JKN lainnya selain huruf a sampai dengan huruf d.

Dalam Pasal 5, Tindakan kecurangan JKN yang dilakukan oleh pemberi pelayanan kesehatan sebagaimana dimaksud dalam Pasal 2 huruf c, dilakukan di: FKTP dan FKRTL.

Tindakan kecurangan JKN yang dilakukan pemberi pelayanan kesehatan di FKTP, meliputi :

a. Memanfaatkan dana kapitasi tidak sesuai dengan ketentuan peraturan perundangundangan;

b. Memanipulasi klaim pada pelayanan yang dibayar secara nonkapitasi;

c. Menerima komisi atas rujukan ke FKRTL; 
d. Menarik biaya dari peserta yang seharusnya telah dijamin dalam biaya kapitasi dan/atau nonkapitasi sesuai dengan standar tarif yang ditetapkan;

e. Melakukan rujukan pasien yang tidak sesuai dengan tujuan untuk memperoleh keuntungan tertentu; dan/atau

f. Tindakan kecurangan JKN lainnya selain huruf a sampai dengan huruf e.

Tindakan kecurangan JKN yang dilakukan pemberi pelayanan kesehatan di FKRTL, meliputi :

a. Penulisan kode diagnosis yang berlebihan / upcoding;

b. Penjiplakan kalim dari pasien lain/cloning;

c. Klaim palsu/ phantom billing;

d. Penggelembungan tagihan obat dan alkes/inflated bills;

e. Pemecahan episode pelayanan/ services unbundling or fragmentation;

f. Rujukan semu/selfs-referals;

g. Tagihan berulang/repeat billing;

h. Memperpanjang lama perawatan/prolonged length of stay;

i. Memanipulasi kelas perawatan/ type of room charge;

j. Membatalkan tindakan yang wajib dilakukan /cancelled services

k. Melakukan tindakan yang tidak perlu/no medical value

1. Penyimpangan terhadap standar pelayanan/standar of care; m. Melakukan tindakan pengobatan yang tidak perlu/unnecessary treatment;

n. Menambah panjang waktu penggunaan ventilator;

o. Tidak melakukan visitasi yang seharusnya/phantom visit;

p. Tidak melakukan prosedur yang seharusnya/phantom procedures;

q. Admisi yang berulang/ readmisi;

r. Melakukan rujukan pasien yang tidak sesuai dengan tujuan untuk memperoleh keuntungan tertentu;

s. Meminta cost sharing tidak seuai dengan ketentuan peraturan perundang-undangan; dan

t. Tindakan kecurangan lainnya selain huruf a sampai dengan huruf $\mathrm{s}$

Dalam Pasal 6, tindakan kecurangan JKN yang dilakukan penyedia obat dan alat kesehatan, meliputi :

a. Tidak memenuhi kebutuhan obat dan/atau alat kesehatan sesuai dengan ketentuan peraturan perundang-undangan;

b. Melakukan kerjasama dengan pihak lain mengubah obat dan/atau alat kesehatan yang tercantum dalam e-catalog dengan harga tidak sesuai dengan e-catalog; dan

c. Melakukan tindakan kecurangan JKN lainnya selain huruf a dan huruf $b$.

\section{Implementasi Kebijakan Pemerintah} Dalam Mencegah Tindakan Fraud Sistem pencegahan kecurangan JKN dalam Peraturan Menteri Kesehatan 
Nomor 36 Tahun 2015, sudah mencakup kegiatan-kegiatan seperti membangun kesadaran, pelaporan, deteksi, investigasi, dan pemberian sanksi. Kegiatan-kegiatan ini sesuai dengan rekomendasi European Comission 2013, bahwa kegiatan anti Fraud harus berjalan sesuai alur seperti skema berikut:

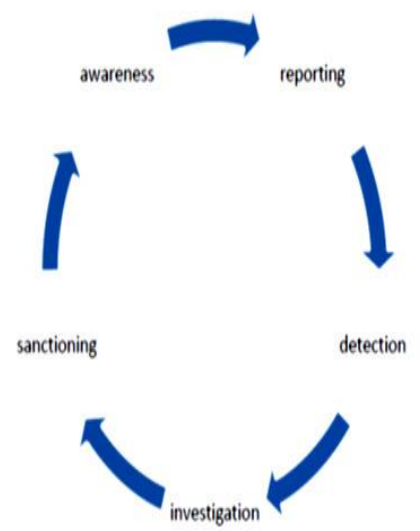

Gambar

\section{Siklus Anti Fraud}

Detil kegiatan dalam siklus anti Fraud adalah sebagai berikut:

1. Pembangunan Kesadaran

Pembangunan kesadaran merupakan kunci untuk mencegah terjadinya atau meluasnya Fraud layanan kesehatan (Buletin WHO,2011). Dalam Perturan Menteri Kesehatan Nomor 36 Tahun 2015, pembangunan kesadaran dapat dilakukan oleh dinas kesehatan kabupaten/ kota dengan pembinaan dan pengawasan dengan melalui program-program edukasi dan sosialisasi.
2. Pelaporan

Pihak yang mengetahui ada kejadian Fraud hendaknya dapat membuat pelaporan. Peraturan Menteri Kesehatan Nomor 36 Tahun 2015 mengamanatkan bahwa pelaporan dugaan Fraud minimalnya mencakup identitas pelapor, nama dan alamat instansi yang diduga melakukan tindakan kecurangan JKN, serta alasan pelaporan. Laporan disampaikan kepada kepala fasilitas kesehatan maupun dinas kesehatan kabupaten/ kota.

3. Deteksi

Dalam Peraturan Menteri Kesehatan Nomor 36 Tahun 2015 deteksi potensi Fraud dapat dilakukan dengan analisa data klaim yang dilakukan dengan pendekatan: mencari anomali data, predictive modeling, dan penemuan kasus. Analisis data klaim dapat dilakukan secara manual dan/atau dengan memanfaatkan aplikasi verifikasi klinis yang terintegrasi dengan aplikasi INA-CBGs. Dalam melakukan analisis data klaim tim pencegahan kecurangan JKN dapat berkoordinasi dengan verifikator BPJS Kesehatan atau pihak lain yang diperlukan.

4. Investigasi

Dalam Permenkes Nomor 36 Tahun 2015 disebutkan bahwa investigasi dilakukan oleh tim investigasi yang 
ditunjuk oleh oleh Tim Pencegahan Kecurangan JKN dengan melibatkan unsur pakar, asosiasi rumah sakit/asosiasi fasilitas kesehatan, dan organisasi profesi. Investigasi dilakukan untuk memastikan adanya dugaan kecurangan JKN, penjelasan mengenai kejadiannya, dan latar belakang atau alasannya.

Pelaporan hasil deteksi dan investigasi dilakukan oleh Tim Pencegahan Kecurangan JKN dan paling sedikit memuat: ada atau tidaknya kejadian Kecurangan JKN yang ditemukan; rekomendasi pencegahan berulangnya kejadian serupa di kemudian hari; dan rekomendasi sanksi administratif bagi pelaku Kecurangan JKN.

5. Pemberian Sanksi/Penindakan

Pemberian sanksi dilakukan untuk menindak pelaku Fraud. Berdasar Peraturan Menteri Kesehatan 36 Tahun 2015, pihak yang berhak memberikan sanksi adalah Menteri, Kepala Dinas Kesehatan Provinsi, dan Kepala Dinas Kesehatan Kabupaten/Kota. Sanksi yang direkomendasikan dalam Permenkes adalah sanksi administrasi dalam bentuk: teguran lisan; teguran tertulis; dan/atau perintah pengembalian kerugian akibat Kecurangan JKN kepada pihak yang dirugikan.
Dalam hal tindakan kecurangan JKN dilakukan oleh pemberi pelayanan, sanksi administrasi dapat ditambah dengan denda paling banyak sebesar 50\% dari jumlah pengembalian kerugian akibat tindakan kecurangan JKN. Bila tindakan kecurangan JKN dilakukan oleh tenaga kesehatan, sanksi administrasi dapat diikuti dengan pencabutan surat izin praktek. Selain sanksi administrasi, kasus Fraud dapat juga dikenakan sanksi pidana yang diatur dalam Pasal 379 jo Pasal 379a jo Pasal 381 KUHP. Walaupun tidak disebut secara langsung dalam pasal-pasal tersebut, namun Fraud dalam JKN dikategorikan sebagai penipuan.

Penelitian yang dilakukan Haneui et.al,2015 mengenai pencegahan, deteksi, dan penindakan Fraud layanan kesehatan kelompok rumah sakit tahun 2015, kegiatan-kegiatan edukasi dan sosialisasi menghasilkan perubahan paradigma dari masing-masing kelompok aktor potensial Fraud. Saat ini sebagian besar kelompok mulai sadar bahwa mereka juga berpotensi melakukan Fraud dan bersedia ambil peran dalam upaya pengendalian Fraud.

Penanganan tindakan kecurangan dalam pelayanan BPJS kesehatan dioptimalkan dengan diterbitkannya Peraturan BPJS Kesehatan Nomor 7 Tahun 2016. Pada Bab II Peraturan BPJS Kesehatan Nomor 7 Tahun 2016, bagian 
keempat tentang siklus pencegahan kecurangan JKN pasal 6, menyebutkan bahwa siklus pencegahan kecurangan pelayanan kesehatan terdiri atas tindakan preventif, pendeteksian, dan penanganan di tingkat peserta, petugas BPJS Kesehatan, dan pemberi pelayanan kesehatan (FKTP/FKRTL),

\section{Strategi Pencegahan Fraud Dalam} Klaim BPJS Kesehatan di masa yang akan datang

Strategi yang diperlukan untuk mencegah tindakan fraud dalam program JKN di masa yang akan datang, meliputi : kesadaran semua pihak yang terkait terhadap potensi fraud melalui regulasi yang memberi batasan atau standar yang jelas untuk membedakan mana tindakan yang dikategorikan fraud atau tidak; menentukan standar pelayanan kedokteran yang diberikan kepada peserta JKN berupa Pedoman Nasional Pelayanan Kedokteran (PNPK) sebagai acuan untuk menilai pelayanan yang diberikan kepada peserta sudah sesuai dengan standar (Syahdu Winda, 2018); meninjau ulang secara berkala paket INA-CBG's dan kapitasi agar sesuai kebutuhan; keseragaman dalam penyediaan dan pemakaian obat dan alat kesehatan yang tercantum dalam fomularium nasional.; memperkuat pengawasan di Kementrian Kesehatan dan BPJS Kesehatan.

\section{PENUTUP}

\section{Kesimpulan}

1. Mekanisme terjadinya fraud yang dilakukan peserta berupa pemalsuan status kepesertaan untuk memperoleh pelayanan kesehatan, bekerjasama dengan pemberi pelayanan dengan memalsukan kondisi kesehatan; yang dilakukan penyelenggara/pemberi pelayanan berupa upcoding, fragmentation, readmisi, no medical value dan type of room charge; sedangkan yang dilakukan oleh pembuat kebijakan BPJS dalam klaim berupa menahan pembayaran ke fasilitas kesehatan/menunggak, kebijakan dari BPJS bahwa penyelenggara (pemberi pelayanan) harus melakukan kerjasama dengan Bank dalam bentuk dana talangan, yang mana bunga dari pinjaman tersebut harus dibayarkan oleh pemberi pelayanan, membayarkan dana kapitasi tidak sesuai dengan ketentuan, bila ada kelebihan pembayaran terhadap pemberi pelayanan, menurut kebijakan BPJS, biaya tersebut harus dikembalikan kepada BPJS. Ternyata fraud tidak hanya dilakukan oleh pemberi pelayanan, namun tindakan ini dapat dilakukan juga oleh peserta BPJS dan pemangku kebijakan BPJS.

2. Implementasi Kebijakan Peraturan Menteri Kesehatan no. 36 Tahun 2015 
dalam mencegah tindakan fraud dilakukan baik di tingkat BPJS Kesehatan, Dinas Kesehatan dan FKRTL melalui penyusunan kebijakan dan pedoman pencegahan kecurangan JKN, pengembangan budaya pencegahan kecurangan JKN melalui pembinaan dan pengawasan yang langsung dilakukan oleh Menteri Kesehatan dan BPJS Kesehatan, pembentukkan tim pencegahan kecurangan JKN di setiap level pelayanan kesehatan dan berbagai pihak yang terkait.

3. Strategi pencegahan tindakan fraud dalam klaim BPJS Kesehatan, agar tidak terjadi lagi kecurangan di masa yang akan datang meliputi : kesadaran semua pihak yang terkait terhadap potensi fraud melalui regulasi yang memberi batasan atau standar yang jelas untuk membedakan tindakan yang dikategorikan fraud. menentukan standar pelayanan kedokteran berupa Pedoman Nasional Pelayanan Kedokteran (PNPK) untuk menilai pelayanan yang diberikan kepada peserta, meninjau ulang secara berkala paket INA-CBG's dan kapitasi agar sesuai kebutuhan; keseragaman dalam penyediaan dan pemakaian obat dan alat kesehatan yang tercantum dalam fomularium nasional.; memperkuat pengawasan di Kementrian Kesehatan dan BPJS Kesehatan.

\section{Saran}

1. Untuk menghindari terjadinya fraud dalam klaim BPJS, diperlukan suatu sistem yang terorganisir dan termonitoring dengan melibatkan seluruh pihak dalam hal ini peserta BPJS, penyelenggara, dan pemangku kebijakan, agar tidak terjadi lagi tindakan kecurangan di masa yang akan datang.

2. Implementasi Permenkes 36/2016 disempurnakan dengan peraturan BPJS Kesehatan Nomor 7 Tahun 2016 dan Permenkes Nomor 16 Tahun 2019, sehingga dalam pelaksanaan Jaminan Kesehatan Nasional tidak terjadi lagi kecurangan.

3. Strategi pencegahan fraud, meliputi kesadaran berbagai pihak mengenai kasus yang berpotensi fraud dan yang tidak; pengelolaan dana kapitasi secara transparan dan pengawasan dalam pembayaran iuran; kepatuhan dalam penggunaan dan penyediaan obat dan alat kesehatan sesuai dengan formularium nasional sebagai kendali mutu dan biaya; pembentukan satgas penanganan fraud sebagai upaya pengawasan program Jaminan Kesehatan Nasional yang bertugas menyusun pedoman penanganan fraud dan melakukan penindakan untuk 
memberikan efek jera bagi pelaku fraud tersebut; mensosialisasikan kebijakankebijakan dalam pencegahan fraud secara berkesinambungan.

\section{DAFTAR PUSTAKA}

\section{A. Buku :}

Hasbullah,Tabrany, Pendanaan Kesehatan dan Alternatif Mobilisasi Dana Kesehatan di Indonesia, Rajagrafindo Persada, Jakarta, 2005.

Johny Ibrahim, Teori \& Metodologi Penelitian Hukum Normatif, Cetakan Ketiga, Bayu Media Publishing, Surabaya, 2005.

Soerjono Soekanto, Penelitian Hukum Normatif Suatu Tinjauan Singkat, 5th ed, Raja Grafindo Persada, Jakarta, 2001.

Vladimir, Rys, Merumuskan Ulang Jaminan

Sosial : Kembali ke Prinsip-Prinsip

Dasar, Pustaka Alfabet, Jakarta, 2011.

Yaslis Ilyas, Fraud : Biaya Terselubung Pelayanan Kesehatan, Pusat Kajian Kesehatan FKM UI, Jakarta, 2015.

\section{B. Jurnal :}

Hubaib Alif Khariza, Program Jaminan Kesehatan Nasional: Studi Deskriptif Tentang Faktor-Faktor Yang Dapat Mempengaruhi Keberhasilan Implementasi Program Jaminan Kesehatan
Nasional Di Rumah Sakit Jiwa Menur Surabaya, Jurnal Kebijakan dan Manajemen Publik Volume 3, Nomor 1, Januari - April 2015.

Hasan Sadikin, Wiku Adisasmito, Analisis Pengaruh Dimensi Fraud Triangle dalam Kebijakan Pencegahan Fraud terhadap Program JKN di RSCM, Jurnal Ekonomi Kesehatan Indonesia, Vol 1 Nomor 2, 2016.

Hanevi Djasri, et.all, Korupsi dalam Pelayanan Kesehatan di Era JKN : Kajian Besarnya Potensi dan Sistem Pengendalian Fraud, Jurnal INTEGRITAS Volume 02 Nomor 1 Tahun 2016.

\section{Perundang-Undangan :}

Undang-Undang Dasar 1945

Undang-Undang nomor 40 Tahun 2004 tentang Sistem Jaminan Sosial Nasional

Permenkes Nomor 36 Tahun 2015 tentang Pencegahan Kecurangan (Fraud) dalam Pelaksanaan Program Jaminan Kesehatan Nasional dalam Sistem Jaminan sosial Nasional.

Peraturan BPJS Kesehatan Nomor 7 Tahun 2016 tentang Sistem Pencegahan Kecurangan (Fraud) dalam Pelaksanaan Program Jaminan Kesehatan.

Permenkes Nomor 16 Tahun 2019 tentang Pencegahan Kecurangan (Fraud) 
Keika Marriska, Strategi Kebijakan Mengurangi Fraud Dalam Klaim Bpjs Ditinjau Dari Permenkes Nomor Tahun...

\section{serta Pengenaan Sanksi}

Administrasi terhadap kecuranagan

(Fraud) dalam pelaksanaan

Program Jaminan Kesehatan

Nasional. 